\title{
Improvement of Huangqi Decoction on Endothelial Dysfunction in 5/6 Nephrectomized Rats
}

\author{
Shuang Chu ${ }^{\mathrm{a}}$ Li Wang ${ }^{\mathrm{a}}$ Xiao-dong Mao ${ }^{\mathrm{a}}$ Wen Peng ${ }^{\mathrm{a}, \mathrm{b}}$ \\ aLaboratory of Renal Disease, b Department of Nephrology, Putuo Hospital, Shanghai University of \\ Traditional Chinese Medicine, Shanghai, China
}

\section{Key Words}

Huangqi Decoction - Oxidative stress - Nitric oxide • Vascular dysfunction • Chronic kidney disease

\begin{abstract}
Background/Aims: Endothelial dysfunction is a major factor in the progression of chronic kidney disease, which correlates with oxidative stress and NO deficiency. Huangqi decoction (HQD) is a potential anti-oxidant ingredient in renoprotection. However, the underlying mechanisms remained identified. Therefore, we investigated whether HQD exhibit improvement in endothelial dysfunction in the 5/6 nephrectomy (Nx) rat model. Methods: Male Wistar rats (180 - $250 \mathrm{~g}$ ) were divided into sham, Nx and Nx + HQD (0.05, 0.15 and $0.45 \mathrm{~g} / \mathrm{kg})$ group, respectively. Renal function and histology were examined with ELISA and Immunohistochemical analysis. Endothelium-dependent relaxation of rat aortas was investigated by isometric tension recordings. Oxidative stress and NO bioavailability were detected by ELISA, DHEstaining, DAF-2 staining and western blotting. Results: Compared with Nx rats, HQD treatment reversed the functional and structural changes of kidney significantly. Besides, endotheliumdependent relaxation of rat aortas was also improved by HQD treatment. NADPH oxidase and ROS generation were inhibited while NO bioavailability was enhanced. Conclusion: HQD can act as a potent prescription for the treatment of endothelium related vascular complications.

\section{Introduction}

Cardiovascular disease risk is one of the most common complications of chronic kidney disease (CKD), and endothelial dysfunction has been shown to be the best predictor of subsequent cardiovascular events [1,2]. Impaired endothelium in uremia, diabetes mellitus, and coronary artery disease are associated with CKD progression [3-5]. Accumulating studies have demonstrated that oxidative stress and inactivation of nitric oxide (NO) play a

S. Chu and L. Wang contribute equally to this work. 


\section{Cellular Physiology Cell Physiol Biochem 2016;40:1354-1366 \\ \begin{tabular}{l|l|l} 
and BOI: 10.1159/000453188 & $\begin{array}{l}\text { C) 2016 The Author(s). Published by S. Karger AG, Basel } \\
\text { www.karger.com/cpb }\end{array}$
\end{tabular} \\ Chu et al.: Huangqi Decoction Ameliorates Endothelial Dysfunction}

fundamental role in the pathogenesis of CKD [6, 7]. Oxidative stress results from increased production of reactive oxygen species (ROS) and decreased antioxidant enzyme capacity. NADPH oxidases are a family of enzymes that is the major source of ROS in the artery wall in conditions such as hypertension, hypercholesterolaemia, diabetes and ageing, and so they are important contributors to the oxidative stress, endothelial dysfunction and vascular inflammation [8]. Besides, reduced activity of endothelial nitric oxide synthase (eNOS) is believed to be associated with vascular dysfunction in diabetes and other disease conditions $[7,9]$. Thus, suppressing oxidative stress and restoration of NO bioactivity are considered as the major strategy for antioxidants in prevention of CKD.

Huangqi Decoction (HQD), which composed of Astragalus (Huangqi), Poria (Fuling), Trichosanthes (Gualou), Ophiopogon (Maidong), Schisandra (Wuweizi), licorice (Gancao), and Rehmannia (Dihuang), is one of the most classic recipes in the clinical treatment of CKD for thousands of years. The most active and predominant components of HQD has been shown to protect against oxidative damage in kidney, liver, heart and brain tissues. For example, Astragalus and its main components potently protected endothelium-dependent relaxation against the acute injury from homocysteine (Hcy), an independent risk factor for vascular endothelial dysfunction, through nitric oxide regulatory pathways [10,11]. Astragalus monomer astragaloside IV combined with ferulic acid exhibit anti-hyperglycemic properties and inhibit vascular endothelial dysfunction in diabetic rats [12]. Trichosanthes extract possess biological potential against oxidative stress [13, 14]. Homoisoflavonoids in different cultivation regions of Ophiopogon exhibit chemical differentiation and anti-oxidant activities [15]. Schisandrin B from schisandra can attenuate myocardial apoptosis, NADPH oxidase subunits and ROS expression in Dox-induced cardiomyopathy [16]. Schisantherin A, another ingredient from schisandra protects against 6-OHDA-induced dopaminergic neuron damage in zebrafish and cytotoxicity in SH-SY5Y cells partly through ROS/NO pathways [17]. Therefore, it is reasonable to assume that HQD can exert antioxidant activities. Although our previous studies have reported that the compound is a promising candidate for renal interstitial fibrosis $[18,19]$, the mechanism of HQD in CKD still need to be further explored. Accordingly, the aim of this study was to examine whether HQD treatment prevents 5/6 Nxinduced endothelial dysfunction and, if so, to determine the underlying mechanism, focusing on the involvement of oxidative stress and NO deficiency.

\section{Material and Methods}

\section{Reagents and materials}

The herbs were provided by Shanghai Huayu Chinese Herbs Co. Ltd. (Shanghai, China). Antibodies of p22phox, p47phox, NOX1, and NOX4 were purchased from Santa Cruz Biotechnology (Santa Cruz, CA, USA); Rac1 and $\beta$-actin were obtained from Cell Signaling Technology (Danvers, MA, USA); eNOS and p-eNOS were provided by Abcam (Cambridge, MA, USA). Goat-anti-rabbit secondary antibodies were brought from Wuhan Boster Biotech Co. Ltd. (Wuhan, China). ECL developer was from Millipore (Billerica, MA, USA). BCA protein quantity kits and PVDF membranes were provided by Pierce (Rockford, IL, USA). Phenylephrine (PE), Acetylcholine (ACh), Sodium nitroprusside (SNP) and Y27632 were purchased from Sigma Chemical Co., Ltd. (St. Louis, MO, USA).

\section{Preparation of $H Q D$}

HQD was composed of crude herbs namely Astragalus (Huangqi, 2 kg), Poris (Fuling, 2 kg), Trichosanthes root (Gualou, $2 \mathrm{~kg}$ ), Ophiopogon (Maidong, $2 \mathrm{~kg}$ ), Schisandra (Wuweizi, $1 \mathrm{~kg}$ ), licorice (Gancao, $1 \mathrm{~kg}$ ), and Rehmannia (Dihuang, $3 \mathrm{~kg}$ ). The extraction was prepared as described previously [19]. In brief, the herb mixture was extracted three times with four times volume of water added, and then the concentration of the decoction was adjusted to $70 \%$ with ethanol overnight. Next the supernatant was collected and dried at $105^{\circ} \mathrm{C}$ for $48 \mathrm{~h}$. The production rate was $13.3 \%$.

\section{KARGER}




\section{Cellular Physiology Cell Physiol Biochem 2016;40:1354-1366

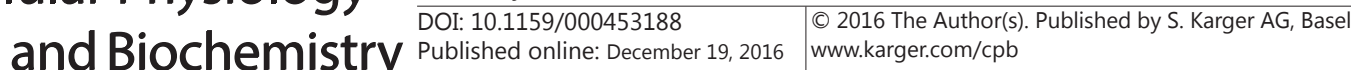 \\ Chu et al.: Huangqi Decoction Ameliorates Endothelial Dysfunction}

\section{Animal model and grouping}

All animal procedures were approved by the Ethics Committee of Putuo Hospital, Shanghai University of Traditional Chinese Medicine. Five-week-old male Wistar rats weighing 180 - 250 g were purchased from Slaccas Co., Ltd. (Shanghai, China). The animals were fed a standard laboratory diet and water ad libituin. At 7 weeks of age, the upper and lower thirds of the left kidney were excised by ligation of renal artery occluded temporarily. One week later, the right kidney was excised. Suspensions of HQD were made in $0.5 \%$ carboxymethylcellulose (CMC) and the compound treatment was initiated at 17-week-old. Rats were randomized into five groups ( $\mathrm{n}=10$ /group). The control group had sham operation. Nx group received vehicle $(0.5 \% \mathrm{CMC})$ and HQD-treated group were gavaged with $0.05,0.15$ and $0.45 \mathrm{~g} / \mathrm{kg}$ daily.

At 6, 12, 16 and 20 week of age, body weight, water intake and food intake were record and systolic blood pressure (SBP) was measured by tail-cuff pletysmography (Shanghai AlcottBiotech, Shanghai, China). At the end of the experimental period, the animals were anesthetized with $50 \mathrm{mg} / \mathrm{kg}$ sodium pentobarbital (i.p.) and blood was collected from the abdominal aorta. The animals were sacrificed and right kidneys were collected for analyses. The animals were kept in the metabolic cages at the beginning of sacrifice for urine collection.

\section{Renal function examination}

Serum and urine were obtained by centrifugation at $2000 \mathrm{~g}$ for $15 \mathrm{~min}$ at $4^{\circ} \mathrm{C}$, aliquoted, and frozen until analysis. Serum creatinine, blood urea nitrogen and urinary protein excretion were examined among different groups with relative colorimetric assay kits (Nanjing Jiancheng Bioengineering Institute, Nanjing, China).

\section{Histopathological analysis}

Kidney tissues were fixed in 4\% paraformaldehyde and embedded in paraffin. Paraffin sections ( $4 \mu \mathrm{m})$ were stained with $0.5 \%$ periodic acid and Schiff (PAS) and Masson. Semiquantitative scoring of glomerular sclerosis in PAS-stained slides and interstitial collagen deposition in Masson-stained slides were performed using method described previously [20].

\section{Measurement of NADPH oxidase activity}

After rats were anesthetized, the thoracic aorta were rapidly removed and stored in $-80^{\circ} \mathrm{C}$. The aortas were lysed in RIPA lysis buffer by sonication on ice. Then the supernatants were collected and protein concentration was determined by BCA protein assay kit (Pierce, Rockford, IL, USA). Equal amounts of protein $(20 \mu \mathrm{g})$ were separated by $10 \%$ SDS polyacrylamide gelelectrophoresis (SDS-PAGE) and transferred to PVDF membrane. Western blot analysis was used to determine the expression of NADPH oxidase subunits including Rac1, p22phox, p47phox, Nox1, and Nox4.

\section{Measurement of ROS generation}

Serum superoxide dismutase (SOD) and malondialdehyde (MDA) were evaluated according to respective ELISA kits (Nanjing Jiancheng Bioengineering Institute, Nanjing, China) as described [21]. Briefly, the level of SOD was assessed by xanthine-xanthine oxidase system to produce superoxide ions, which reacted with 2-(4-iodophenyl)-3-(4-nitrophenol-5-phenlyltetrazolium chloride) to form red formazan dye, and the final products at $550 \mathrm{~nm}$ were measured. MDA activity was assessed by thiobarbituric acid (TBA) method as commercially recommended. MDA reacts with TBA at $90-100^{\circ} \mathrm{C}$ in acidic condition and the reaction yields pink TBA reactive substances (TBARS), which was measured at $532 \mathrm{~nm}$.

In situ intracellular superoxide observation was achieved using fluorescence probe dihydroethidium (DHE), which can be oxidized by superoxide to ethidium bromide, thus yielding fluorescence by forming complexes with DNA, according to earlier reports [22]. Frozen thoracic aortas were cut into $4 \mu \mathrm{m}$ thickness slices. DHE $(10 \mu \mathrm{M})$ was directly added onto the slices, incubated for $30 \mathrm{~min}$ at $37{ }^{\circ} \mathrm{C}$, and then washed with PBS to remove free DHE molecules. Fluorescence was monitored via a fluorescence microscope (Nikon TE2000, Japan).

\section{Measurement of NO activity}

Homogenates of rat aortic were harvested and NO was determined nonisotopically using a commercial assay kit (Nanjing Jiancheng Bioengineering Institute, Nanjing, China). The supernatants of homogenates 


\section{Cellular Physiology Cell Physiol Biochem 2016;40:1354-1366 \begin{tabular}{l|l|l} 
and Biochemistry $\begin{array}{l}\text { DOI: 10.1159/000453188 } \\
\text { Published online: December 19, } 2016\end{array}$ & $\begin{array}{l}\text { (c) } 2016 \text { The Author(s). Published by S. Karger AG, Basel } \\
\text { www.karger.com/cpb }\end{array}$
\end{tabular} \\ Chu et al.: Huangqi Decoction Ameliorates Endothelial Dysfunction}

were collected for extraction of total protein with RIPA lysis buffer. The concentration of extracted protein was determined using BCA kits. Then SDS-PAGE was performed with $20 \mu \mathrm{g}$ of protein sample to determine the expression of eNOS and p-eNOS. Direct visualization of NO production was realized by $4 \mu \mathrm{m}$ thickness slices of frozen aortic rings incubating with 4, 5-diaminofluorescein diacetate (DAF-2 DA, $10 \mu \mathrm{M}$ ) as previously described [23]. The following procedure was similar with the protocol of DHE staining and green fluorescence was monitored.

Preparation of aortic rings and vascular reactivity protocol

The thoracic aorta of rats were rapidly removed and placed in oxygenated Krebs solution $\left(4^{\circ} \mathrm{C}\right)$ containing following compositions (mM): $118.0 \mathrm{NaCl}, 4.7 \mathrm{KCl}, 1.2 \mathrm{MgCl}_{2} .6 \mathrm{H}_{2} \mathrm{O}, 1.2 \mathrm{KH}_{2} \mathrm{PO}_{4}, 25.0 \mathrm{NaHCO}_{3}$, $2.5 \mathrm{CaCl}_{2}$ and 11 glucose ( $\mathrm{pH} 7.4$ ). Aorta was cleaned of connective tissues and cut into 3-mm rings and then suspended by two stainless steel hooks in $10 \mathrm{ml}$ organ chambers filled with Krebs solution $\left(37^{\circ} \mathrm{C}\right.$, oxygenated with $95 \% \mathrm{O}_{2}$ and $5 \% \mathrm{CO}_{2}$ ). The tension was recorded with a force transducer and Power Lab recording system (AD Instruments Pty Ltd).

All rings were set to $3 \mathrm{~g}$ and equilibrated at $37^{\circ} \mathrm{C}$ for $60 \mathrm{~min}$ before experiments and then exposured to $60 \mathrm{mM} \mathrm{KCl}$. After elution and a further equilibration, the integrity of the endothelium was determined by $\mathrm{ACh}\left(10^{-6} \mathrm{M}\right)$ to induce more than $80 \%$ relaxation of rings pre-contracted with $\mathrm{PE}\left(3 \times 10^{-7} \mathrm{M}\right)$. To assess endothelial-dependent vasorelaxation, cumulative concentration-response curves were generated with ACh $\left(10^{-10}\right.$ to $\left.10^{-4} \mathrm{M}\right)$ pre-contracted with PE. Endothelial-independent vasorelaxation by SNP was assessed in the same rings constricted with PE. Vasoconstriction was assessed by $\mathrm{PE}\left(10^{-9}\right.$ to $\left.3 \times 10^{-5} \mathrm{M}\right)$ and $\mathrm{KCl}$ (5 to 80 $\mathrm{mM}$ ) in the same rings. To investigate the role of ROCK in endothelial dysfunction, rings were pre-contracted with PE and treated with increasing concentrations of a ROCK inhibitor Y27632 (10 $10^{-9}$ to $\left.10^{-6} \mathrm{M}\right)$.

\section{Statistical analysis}

Responses to ACh and SNP were represented as \% of the maximal contraction to PE. The concentration of ACh that induced $50 \%$ of the maximal relaxation was regarded as the $\mathrm{EC}_{50}$ which determined by regression analysis of the log dose-response curves. $\mathrm{EC}_{50}$ was expressed as pD2 (-log $\left.\mathrm{EC}_{50}\right)$. All data were expressed as mean \pm SEM. Statistical analysis was performed via Student's unpaired t test between two groups or OneWay Analysis of Variance (ANOVA) with Tukey's post-hoc test among more than two groups (GraphPad Prism 5.0 software, GraphPad Prism software Inc., San Diego, Calif, USA). P $<0.05$ was considered statistically significant.

\section{Results}

Effect of HQD on physiological parameters, renal function and histology in 5/6 nephrectomy rats

As shown in Fig. 1A, Nx group had lower body weight vs. sham group at 12, 16 and 20 week significantly $(\mathrm{p}<0.001)$. Conversely, HQD restored the decline dose-dependently, especially at 20 week (Nx + HQD 0.45: $271.33 \pm 27.7 \mathrm{~g}$ vs. Nx: $226.5 \pm 23.9 \mathrm{~g}, \mathrm{p}<0.001$ ). Water intake showed the same tendency as body weight (Fig. 1B). Although no significant changes occurred in food intake, SBP and blood urea nitrogen in HQD-treated group compared with Nx group, serum creatinine decreased dramatically at HQD $0.45 \mathrm{~g} / \mathrm{kg}(\mathrm{p}<0.05)$. Notably, the inhibitory efficacy is more obvious in urinary protein excretion $(\mathrm{p}<0.001)$.

Kidney pathological changes were observed in Fig. 2. In Fig. 2A, Nx rats developed significant glomerulosclerosis and tubular atrophy, dilation and epithelial hyperplasia as expected. Fig. 2B showed that the glomerular sclerosis score increased significantly in $\mathrm{Nx}$ rats compared with sham rats $(\mathrm{P}<0.001)$, and this increase was decreased with HQD treatment in a dose-dependent manner $(\mathrm{p}<0.05)$. Figure $2 \mathrm{C}$ also showed that $\mathrm{Nx}$ can develop extensive interstitial fibrosis as manifested in the Masson's trichrome-stained kidney sections compared with sham group. However, treatment with HQD decreased the collagen deposition. Semiquantitative histomorphometry analysis demonstrated that HQD treatment ameliorated significantly the pathological changes from $19 \%$ in the Nx groups to $12 \%$ in the $\mathrm{Nx}+\mathrm{HQD} 0.15 \mathrm{~g} / \mathrm{kg}(\mathrm{p}<0.05)$ group and $10 \%$ in the $\mathrm{Nx}+0.45 \mathrm{~g} / \mathrm{kg}(\mathrm{p}<0.01)$ group, respectively (Fig. 2D). 


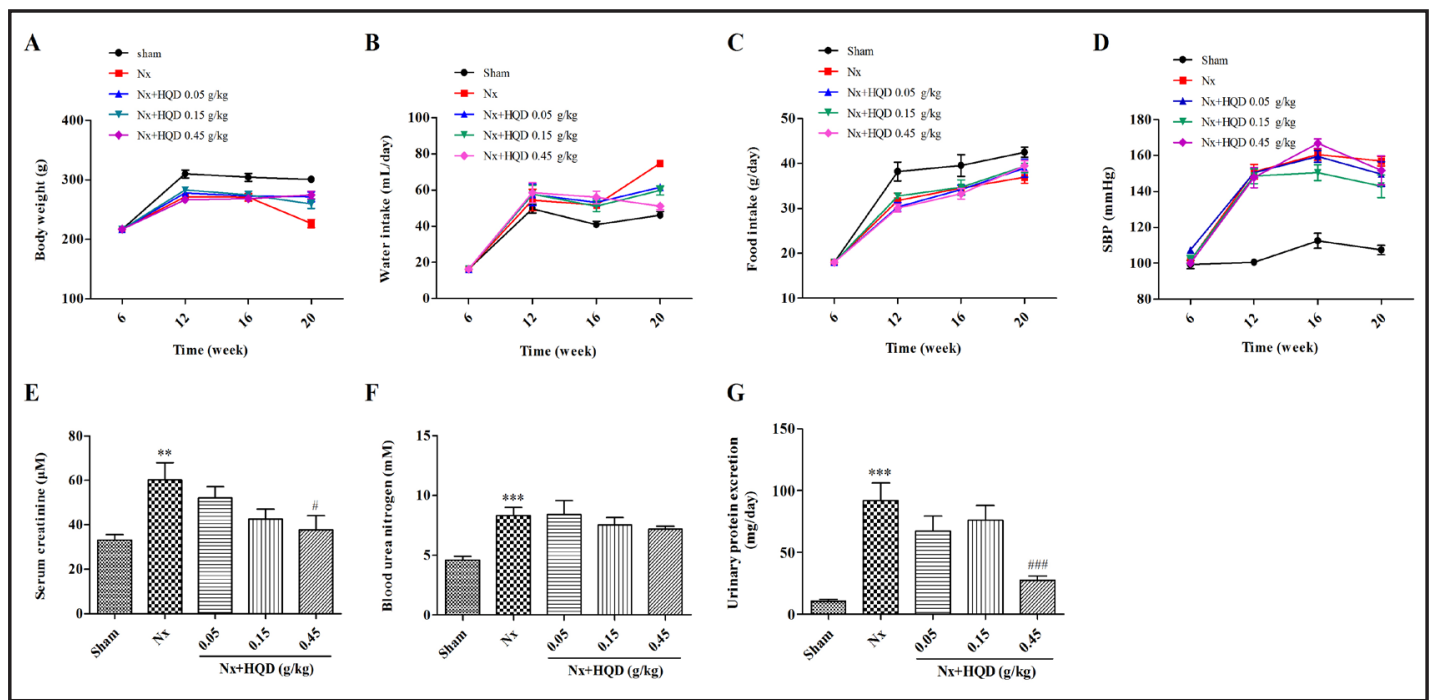

Fig. 1. Effect of HQD on (A) Body weight (g). (B) Water intake (ml/day). (C) Food intake (g/day). (D) SBP $(\mathrm{mmHg})$. (E) serum creatinine $(\mu \mathrm{M})$. (F) Blood urea nitrogen (mM). (G) Urinary protein excretion (mg/day) in Sham-operated (control), untreated 5/6 nephrectomized (Nx) and HQD (0.05, 0.15, 0.45 g/kg)-treated $5 / 6$ nephrectomized $(\mathrm{Nx}+\mathrm{HQD})$ rats. Symbols indicate mean \pm SEM for $\mathrm{n}=6-8$ animals; ${ }^{* *} \mathrm{p}<0.01,{ }^{* * *} \mathrm{p}<$ 0.001 , compared with sham group. \# p < 0.05, \#\# $\mathrm{p}<0.001$, compared with Nx group.

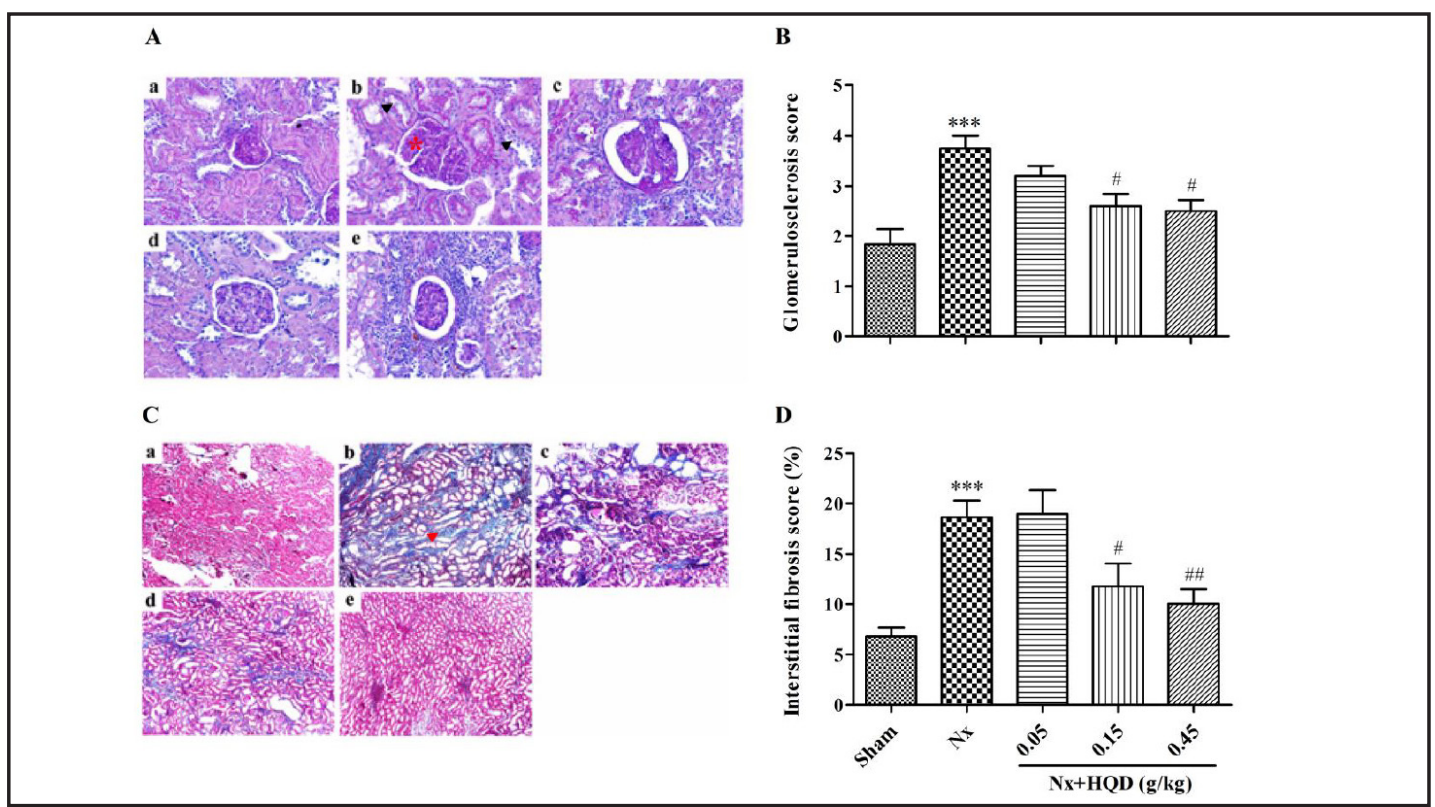

Fig. 2. Effect of HQD on renal injuries in Nx rats. (A and C) Representative photomicrographs of PAS- and Masson's trichrome-stained kidney sections from the Sham (a), Nx (b) and Nx+HQD 0.05, 0.15, $0.45 \mathrm{~g} / \mathrm{kg}$ (c-e) groups. (Magnification, $\times 400$ ). (B and D) Analysis of glomerulosclerosis scores and interstitial fibrosis scores. Symbols indicate mean \pm SEM for $\mathrm{n}=6-8$ animals; ${ }^{* *} \mathrm{p}<0.001$, compared with sham group. \# $\mathrm{p}<$ 0.05 , \#\#P $<0.01$ compared with Nx group. The asterisk indicates glomerulosclerosis, the black arrow indicates tubular atrophy, dilation and epithelial hyperplasia and the red arrow indicates interstitial fibrosis (blue collagen deposition in interstitium).

\section{Effect of $H Q D$ on vascular reactivity}

As shown in Fig. 3A, B cumulative addition of PE $\left(10^{-9}\right.$ to $\left.3 \times 10^{-5} \mathrm{M}\right)$ and $\mathrm{KCl}$ (5 to 80 $\mathrm{mM}$ ) to the organ bath resulted in concentration dependent contractions of aorta in all the groups. Although no change in the maximum response $\left(\mathrm{E}_{\max }\right)$ and $\mathrm{pD}_{2}$ in response to 
Fig. 3. Response of aortas isolated from sham, $\mathrm{Nx}$ and $\mathrm{Nx}+\mathrm{HQD}(0.05,0.15$. $0.45 \mathrm{~g} / \mathrm{kg}$ ) rats to (A) phenylephrine (PE), (B) $\mathrm{KCl}$, (C) acetylcholine (ACh) and (D) sodium nitroprusside (SNP). Symbols indicate mean \pm SEM for $\mathrm{n}=6-8$ animals; *P $<0.05$, ** $\mathrm{P}<0.01$ compared with sham group; \#P $<0.05$, \#\#P <0.01 compared with $\mathrm{Nx}$ group.

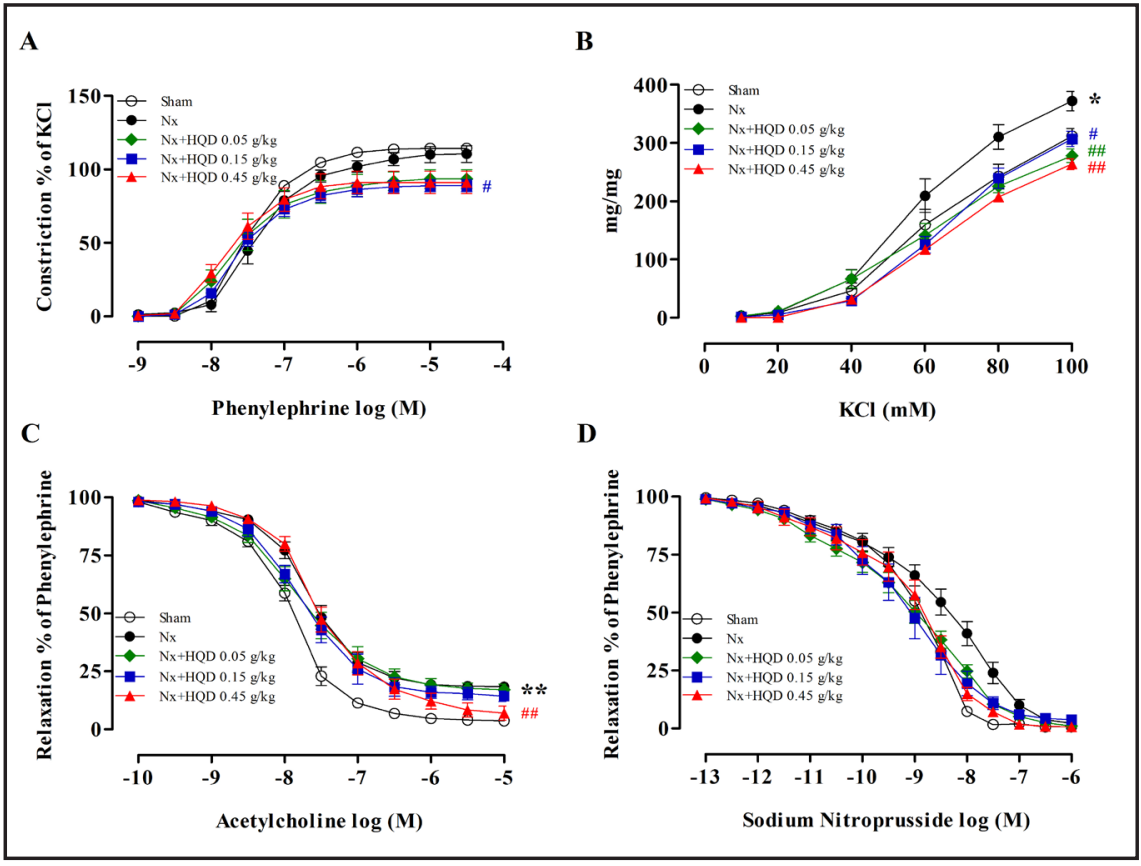

Table 1. Effect of HQD on the maximal response $\left(\mathrm{E}_{\max }\right.$ ) values of $\mathrm{PE}, \mathrm{KCl}, \mathrm{ACh}$ and SNP dose response curves of the aortas isolated from sham, 5/6 nephrectomized ( $\mathrm{Nx})$ rats, HQD $(0.05,0.15,0.45 \mathrm{~g} / \mathrm{kg})$ rats. Valves are mean \pm SEM for $\mathrm{n}=6$ - 8 animals; ${ }^{*} \mathrm{P}<0.05$, ${ }^{* *} \mathrm{P}<0.01$ compared with sham group; ${ }^{*} \mathrm{P}<0.05,{ }^{\# \#} \mathrm{P}<0.01$ compared with Nx group

\begin{tabular}{llllll}
\hline$E_{\max }$ & Sham & $\mathrm{Nx}$ & $\mathrm{Nx}+\mathrm{HQD}$ & $\mathrm{Nx}+\mathrm{HQD}$ & $\mathrm{Nx}+\mathrm{HQD}$ \\
& & & $0.05 \mathrm{~g} / \mathrm{kg}$ & $0.15 \mathrm{~g} / \mathrm{kg}$ & $0.45 \mathrm{~g} / \mathrm{kg}$ \\
\hline $\mathrm{PE}$ & $114.33 \pm 4.60$ & $110.54 \pm 5.69$ & $93.52 \pm 6.42$ & $88.91 \pm 4.06^{\#}$ & $91.09 \pm 7.69$ \\
$\mathrm{ACh}$ & $96.33 \pm 4.28$ & $81.65 \pm 4.16^{* *}$ & $82.87 \pm 7.07$ & $85.84 \pm 5.47$ & $93.03 \pm 7.46^{\# \#}$ \\
SNP & $99.30 \pm 0.70$ & $97.78 \pm 1.30$ & $98.90 \pm 0.73$ & $96.78 \pm 1.52$ & $99.34 \pm 0.66$ \\
$\mathrm{KCl}$ & $311.63 \pm 13.19$ & $371.93 \pm 16.65^{*}$ & $278.42 \pm 11.40^{\# \#}$ & $307.15 \pm 13.06^{\#}$ & $263.80 \pm 9.28_{\# \#}$ \\
\hline
\end{tabular}

Table 2. Effect of HQD on the $\mathrm{pD}_{2}\left(-\log \mathrm{EC}_{50}\right)$ values of $\mathrm{PE}, \mathrm{ACh}$ and SNP dose response curves of the aortas isolated from sham, $5 / 6$ nephrectomized $(\mathrm{Nx})$ rats, HQD $(0.05,0.15,0.45 \mathrm{~g} / \mathrm{kg})$ rats. Valves are mean \pm SEM for $\mathrm{n}=6$ - 8 animals; ${ }^{*} \mathrm{P}<0.05,{ }^{* *} \mathrm{P}<0.01$ compared with sham group; ${ }^{\mathrm{P}}<0.05$, ${ }^{\#} \mathrm{P}<0.01$ compared with Nx group

\begin{tabular}{|c|c|c|c|c|c|}
\hline $\begin{array}{l}\mathrm{pD}_{2} \\
\text { ( } 95 \% \text { confidence interval) }\end{array}$ & Sham & $\mathrm{Nx}$ & $\mathrm{NX}+\mathrm{HQD} 0.05 \mathrm{~g} / \mathrm{kg}$ & $\mathrm{NX}+\mathrm{HQD} 0.15 \mathrm{~g} / \mathrm{kg}$ & $\mathrm{NX}+\mathrm{HQD} 0.45 \mathrm{~g} / \mathrm{kg}$ \\
\hline PE & $\begin{array}{l}7.466 \\
(7.354-7.578)\end{array}$ & $\begin{array}{l}7.352 \\
(7.222-7.482)\end{array}$ & $\begin{array}{l}7.669 \\
(7.420-7.919)\end{array}$ & $\begin{array}{l}7.604 \\
(7.488-7.720)\end{array}$ & $\begin{array}{l}7.766^{\#} \\
(7.542-7.989)\end{array}$ \\
\hline $\mathrm{ACh}$ & $\begin{array}{l}7.903 \\
(7.840-7.966)\end{array}$ & $\begin{array}{l}7.658^{*} \\
(7.573-7.743)\end{array}$ & $\begin{array}{l}7.82 \\
(7.674-7.966)\end{array}$ & $\begin{array}{l}7.721 \\
(7.582-7.860)\end{array}$ & $\begin{array}{l}7.554 \\
(7.449-7.658)\end{array}$ \\
\hline SNP & $\begin{array}{l}8.894 \\
(8.789-8.998)\end{array}$ & $\begin{array}{l}8.114^{* *} \\
(7.782-8.445)\end{array}$ & $\begin{array}{l}8.864 \# \# \\
(8.650-9.077)\end{array}$ & $\begin{array}{l}9.095 \# \# \\
(8.861-9.328)\end{array}$ & $\begin{array}{l}8.826^{\#} \\
(8.650-9.001)\end{array}$ \\
\hline Y27632 & $\begin{array}{l}6.519 \\
(6.340-6.697)\end{array}$ & $\begin{array}{l}7.33^{* *} \\
(7.124-7.536)\end{array}$ & $\begin{array}{l}7.334 \\
(7.133-7.534) \\
\end{array}$ & $\begin{array}{l}7.53 \\
(7.343-7.716)\end{array}$ & $\begin{array}{l}6.548 \# \# \\
(6.353-6.743) \\
\end{array}$ \\
\hline
\end{tabular}

$\mathrm{PE}, \mathrm{Nx}$ rats resulted in a large increase in aorta responsiveness to $\mathrm{KCl}$, which reflected by a significant increase in $\mathrm{E}_{\max }(\mathrm{P}<0.05$, Fig. 3A, B, Table 1, 2). However, HQD administration at $0.05,0.15$ and $0.45 \mathrm{~g} / \mathrm{kg}$ normalized the aorta $\mathrm{E}_{\max }$ response to $\mathrm{KCl}$, respectively $(\mathrm{P}<0.05$, Fig. 3B, Table 1).

Aortas removed from $\mathrm{Nx}$ rats displayed reduced $\mathrm{E}_{\max }$ and sensitivity $\left(\mathrm{pD}_{2}\right)$ to $\mathrm{ACh}$ compared with sham group ( $\mathrm{P}<0.05$, Fig. 3C, Table 1, 2). In contrast, there was no difference in $\mathrm{E}_{\max }$ in response to SNP between sham and Nx group (Fig. 3D, Table 1). Besides, impairment 


\section{Cellular Physiology Cell Physiol Biochem 2016;40:1354-1366

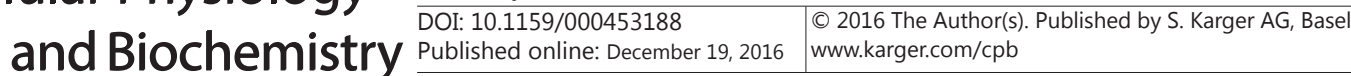 \\ Chu et al.: Huangqi Decoction Ameliorates Endothelial Dysfunction}

Fig. 4. Effect of HQD on NADPH oxidase. (A) Western blot for NADPH oxidase subunits including Rac1, p22phox, p47phox, NOX1 and NOX4. (B-F) Statistical analysis of A. Symbols indicate mean \pm SEM for $n=4-6$ animals; ${ }^{* * *} \mathrm{p}<0.001$, compared with sham group; \#\# $\mathrm{p}<0.01$, \#\#\# p $<0.001$, compared with $\mathrm{Nx}$ group.

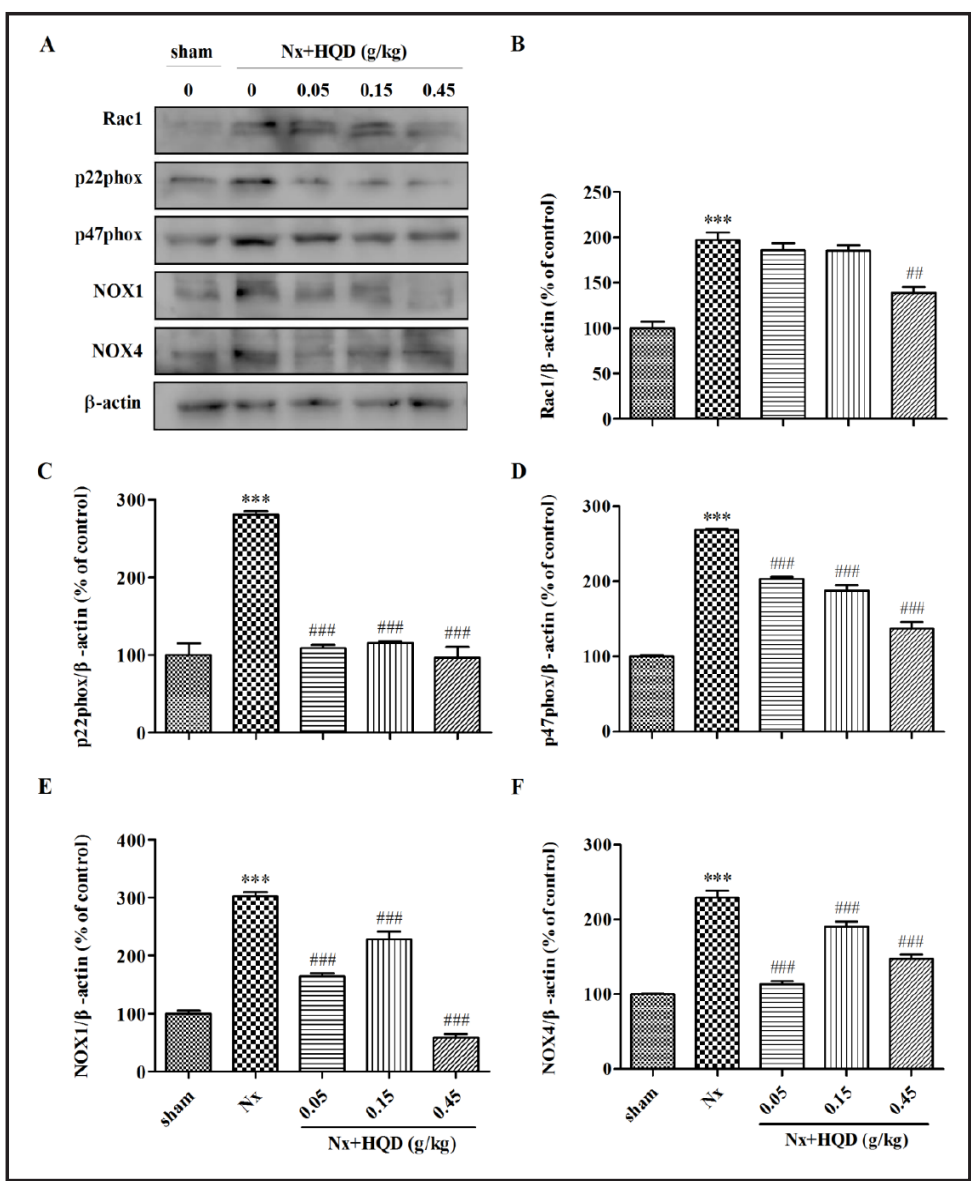

in isolated aorta response to $\mathrm{ACh}$ from $\mathrm{Nx}$ rats was prevented by in vivo treatment with $\mathrm{HQD}$ at $0.45 \mathrm{~g} / \mathrm{kg}(\mathrm{P}<0.01$, Fig. $3 \mathrm{C}$, Table 1$)$.

\section{Effect of HQD on NADPH oxidase}

As shown in Fig. 4, expression of NADPH oxidase subunits including Rac1, p22phox and $\mathrm{p} 47$ phox increased significantly in Nx group compared with sham group $(\mathrm{p}<0.001)$. However, HQD inhibited the expression of those subunits, the most dramatically efficacy exist in HQD at $0.45 \mathrm{~g} / \mathrm{kg}(\mathrm{p}<0.01)$. Similar changes were also observed in NOX1 and NOX4 expression.

\section{Effect of HQD on ROS generation}

To test the level of ROS, activities of serum SOD were first examined (Fig. 5A). Compared with the sham group, Nx rats showed decreased level of SOD but HQD exerted opposite efficacy and almost remarkably at $0.45 \mathrm{~g} / \mathrm{kg}(\mathrm{p}<0.05)$. The serum levels of MDA, a marker of lipid peroxidation induced by ROS, were increased in Nx rats compared to the sham group ( $p$ $<0.001)$. In contrast, administration of HQD suppressed the process significantly ( $p<0.05)$.

To characterize and localize ROS content within the vascular wall, ethidium red fluorescence was analyzed in sections of aorta incubated with DHE (Fig. 5C). As analyzed of fluorescence intensity in Fig. 5D, rings from Nx rats showed marked increased red staining compared to sham rats, which was prevented by HQD at 0.15 and $0.45 \mathrm{~g} / \mathrm{kg}(\mathrm{p}<0.01)$.

\section{Effect of HQD on NO generation}

Phosphorylated eNOS (p-eNOS) is the active form of eNOS, so the two proteins were examined in aorta ring. As shown in Fig. 6A, B, compared with Nx group the level of p-eNOS and eNOS increased with the HQD treatment, especially significant at $0.45 \mathrm{~g} / \mathrm{kg}(\mathrm{p}<0.001)$. 


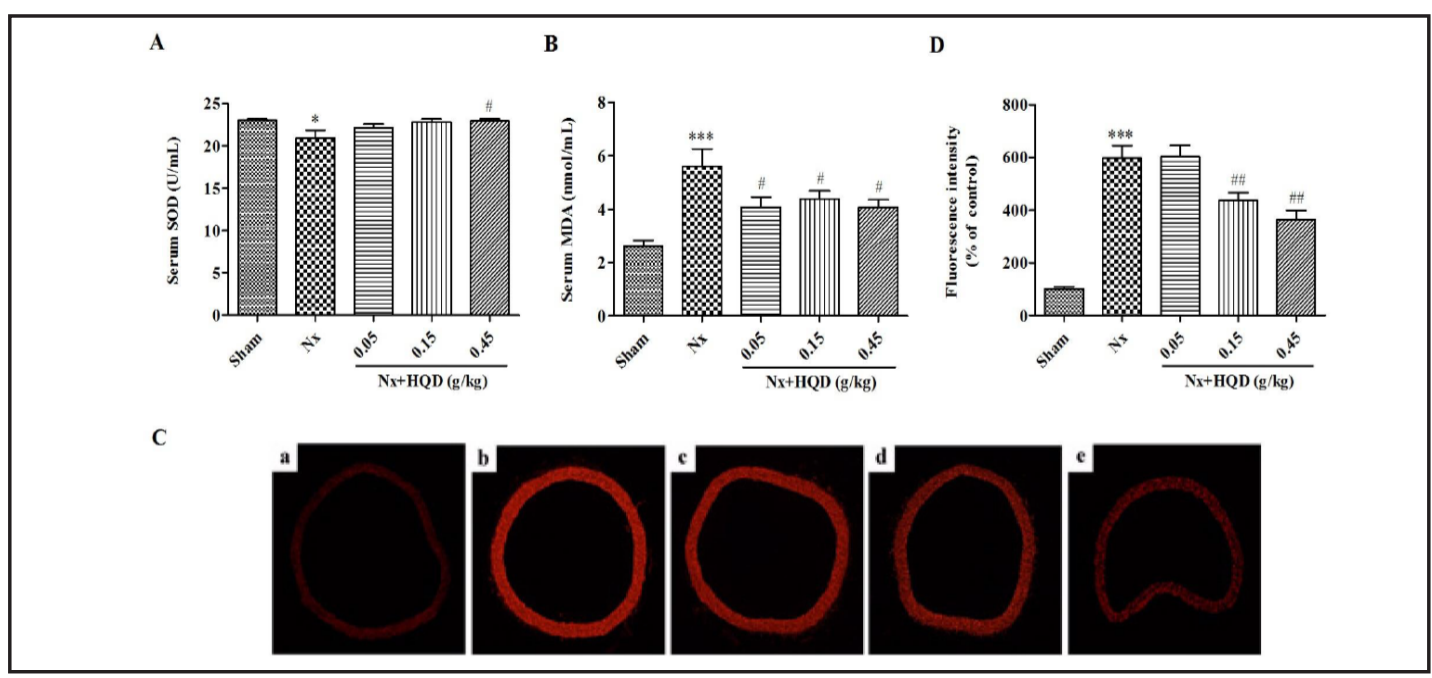

Fig. 5. Effect of HQD on ROS generation. (A) SOD (U/ml). (B) MDA (mmol/ml). (C) Representative photomicrographs of DHE-stained thoracic aorta sections from the Sham (a), Nx (b) and Nx+HQD 0.05, 0.15, 0.45 $\mathrm{g} / \mathrm{kg}(\mathrm{c}-\mathrm{e})$ groups (Magnification, $\times 200$ ). D, Analysis of fluorescence intensity of ROS from C. Symbols indicate mean \pm SEM for $\mathrm{n}=6-8$ animals; ${ }^{*} \mathrm{p}<0.05$, ${ }^{* * *} \mathrm{p}<0.001$, compared with sham group. \# $\mathrm{p}<0.05$, \#\# $\mathrm{p}$ $<0.01$, compared with Nx group.

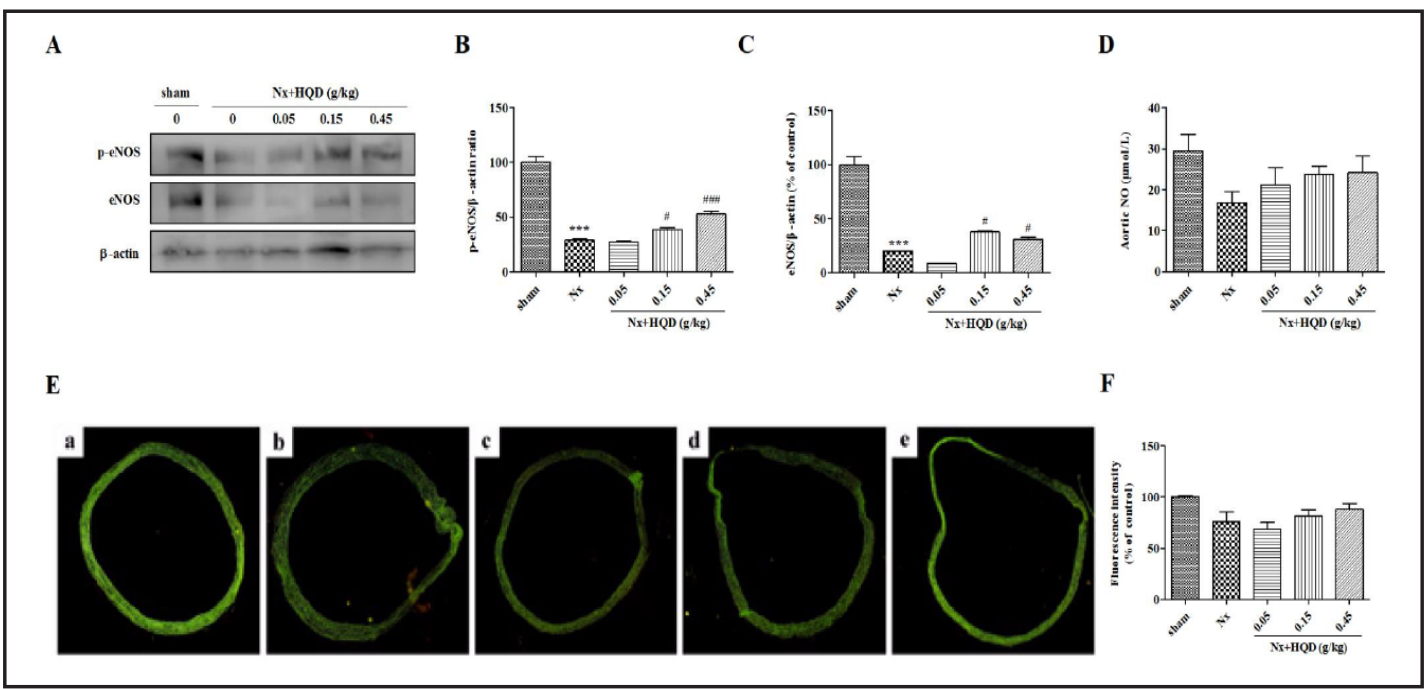

Fig. 6. Effect of HQD on NO generation. (A) Western blot for p-eNOS and eNOS. (B, C) Analysis of p-eNOS and eNOS from A. (D) NO ( $\mu \mathrm{M} / \mathrm{L}$ ) in Aortic. (E) Representative photomicrographs of DAF-2-stained thoracic aorta sections from the Sham (a), Nx (b) and Nx+HQD 0.05, 0.15, 0.45 g/kg (c-e) groups (Magnification, $x$ 200). (F) Analysis of fluorescence intensity of NO from E. Symbols indicate mean \pm SEM for $n=4-6$ animals; ${ }^{* * *} \mathrm{p}<0.001$, compared with $\mathrm{Nx}$. \# $\mathrm{p}<0.05$, \#\#\# $\mathrm{p}<0.001$, compared with $\mathrm{Nx}+\mathrm{HQD}(0.05 \mathrm{~g} / \mathrm{kg})$ rats.

Although no dramatic difference detected between $\mathrm{Nx}$ and HQD-treatment groups in aortic NO level and activity with ELISA and DHE-staining detection, similar tendency was also observed (Fig. 5D-F). The increased changes suggest the potential efficacy of HQD on endothelial layer of aorta.

In endothelial dysfunction, ROCK inhibition may be responsible for the relaxation response to NO, so a ROCK inhibitor Y27632 was introduced. As shown in Fig. 7, Nx rats exhibited a dramatic decrease in $\mathrm{pD}_{2}$ value compared with sham group $(\mathrm{p}<0.01)$. While, 
Fig. 7. Response of aortas isolated from sham, $\mathrm{Nx}$ and $\mathrm{Nx}+\mathrm{HQD} 0.05,0.15 .0 .45 \mathrm{~g} / \mathrm{kg}$ rats to ROCK inhibitor Y27632. Symbols indicate mean \pm SEM for $n$ $=4-6$ animals.

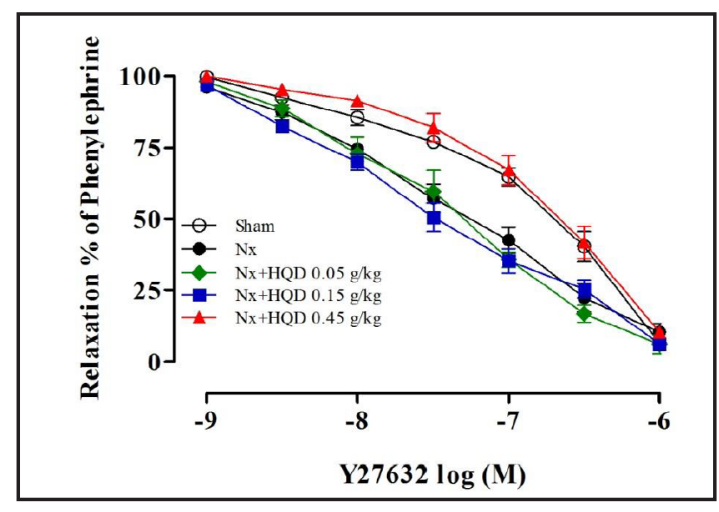

$\mathrm{HQD}$ administration at $0.45 \mathrm{~g} / \mathrm{kg}$ restored the impaired $\mathrm{pD}_{2}$ response of aortas to $\mathrm{Y} 27632$ significantly ( $p<0.01$, Fig. 7, Table 2).

\section{Discussion}

In the present study, we first demonstrate that HQD has the ability in reversing functional and structural alterations in rats with 5/6 Nx, and the biological activity was associated with attenuation of NADPH oxidase expression, ROS production and promoting NO production.

$5 / 6$ nephrectomized rat is a well-established model having a significant reduction in renal mass along with hypertension, proteinuria, glomerulosclerosis and tubulointerstitial injury. Besides, in our study $\mathrm{Nx}$ rats were charactered with endothelial dysfunction, evidenced by a relaxant response to $\mathrm{ACh}$, which corresponding to the previous experimental investigations [24-27]. Clinical study also showed that atherosclerosis can be accelerated in patient with impaired endothelium-dependent vasodilatation [28]. Given these results, renal mass reduction features progressive injury to the renal microvascular endothelium, resulting to glomerular sclerosis and other injuries [25]. In our study, although HQD had no effect on the increased systolic blood pressure in Nx rats, the treatment can still significantly reverse the functional and structural alterations found in rats with 5/6 Nx, which suggest the beneficial effect of this compound in renoprotection. Meanwhile, HQD treatment not only increased the aorta responsiveness to $\mathrm{KCl}$, but to ACh versus no effect to SNP, which indicate the potential correlation between HQD efficacy and endothelial-dependent mechanism in Nx rats.

Previous studies have showed that some antioxidant compounds, such as $\mathrm{N}$-acetylcysteine, melatonin, $\mathrm{S}$-allylcysteine, vitamin $\mathrm{E}$ and curcumin are potential candidate in inhibiting renal dysfunction [20, 29-32]. In the present study, as expected, HQD decreased the expression of NADPH oxidase significantly, so HQD may exert efficacy through suppressing oxidative stress. In vascular cells, the NADPH oxidase possesses cytosolic subunits (p47phox, p67phox, or homologs) and membrane-bound subunits (NOX-1,-2,-4,-5 and $\mathrm{p} 22$ phox), which form a functional enzyme complex upon activation [8,33]. Both NADPH oxidase activity and NADPH oxidase subunit expression are increased in vascular disease, so NADPH oxidase is considered as therapeutic targets [8]. The primary catalytic function of the NADPH oxidase family of enzymes is the generation of ROS. In 5/6 Nx mice, treatment with an SOD/catalase mimetic prevented aortic oxidative stress [3]. SOD activity is lower in the blood of stress-sensitive rats compared with that of Wistar rats, which consistent with our finding of decreased SOD level in 5/6 Nx. The functional importance of ROS in leading to hypertension has been suggested by the fact that tempol or heparin-binding SOD, which localizes within the vessel wall [34]. Similar findings have been demonstrated in deoxycorticosterone acetate (DOCA)-salt hypertension and in renovascular hypertensive rats $[35,36]$. In the model of chronic infusion of angiotensin II in rats, the NADPH subunit p22phox mRNA is up-regulated. Both hypertension and the increase in p22phox mRNA are 
prevented by pretreatment with SOD [37]. Evidence also exists that erythrocyte SOD activity is reduced and antioxidant therapy improves endothelial function [38, 39]. Corresponding to those findings, our study identified HQD can reverse the abnormal increase of NADPH oxidase and ROS, and serum SOD also increased with HQD treatment at $0.45 \mathrm{~g} / \mathrm{kg}$ in 5/6 Nx. So HQD exert efficacy in vascular function may through oxidative stress pathway.

Endothelial dysfunction is usually accompanied by cardiovascular events such as hypertension in the process of CKD. The integrity of the vascular function and the bioavailability of NO could play a pivotal role in vascular homeostasis and its alteration is involved in an increased basal tone. Another factor that could alter the basal tone is the oxidative stress through inactivation of $\mathrm{NO}$ and alteration of vascular reactivity [40]. Moreover, the oxidative stress may also produce a direct vasoconstrictor effect accompanied to an increase of myogenic tone [41]. NADPH oxidase is a source of superoxide anion in the vessel wall. Superoxide anion is involved in increased blood pressure, vascular hypertrophy, and endothelial dysfunction and plays a role in the development of spontaneous vascular tone $[42,43]$. Because superoxide and NO have counterbalancing actions and reciprocally reduce each other's bioavailability, an imbalance of NO and superoxide may shift the kidney toward a state of superoxide dominance, causing renal vasoconstriction, enhanced tubular sodium reabsorption, and CKD progression [6]. In our study, HQD can increase both p-eNOS and eNOS expression and aortic NO abundance, which reveal the positive effect of HQD on NO bioavailability.

Decrease of NO bioavailability often associated with decline of endothelium-dependent vasodilatation under various pathological conditions [40]. Our present data showed that $\mathrm{HQD}$ at $0.45 \mathrm{~g} / \mathrm{kg}$ ameliorated the impaired ACh-induced relaxations in rats with $5 / 6 \mathrm{Nx}$, while exerted no change to the effect of SNP. On the basis of the data, it seems that HQD efficacy is endothelium-dependent and NO-relevant. NO is released from endothelial cells and evidence was presented that RhoA/Rho-kinase (ROCK) pathway involved in the mechanical activity of arteries [44-46]. Diabetes-induced vascular dysfunction can arise due to either inhibition of eNOS, thereby less endothelial NO-production, in part, due to an upregulation of ROCK by hyperglycemia [46]. Here, we used ROCK inhibitor of Y27632 to test whether the pathway involved in HQD activity. Interestingly, HQD administration at $0.45 \mathrm{~g} / \mathrm{kg}$ decreased the response of aortas to Y27632, which confirmed our hypothesis. However, previous studies demonstrated that ROCK pathway is much more active following long-term (eNOS KO) versus short-term (short-eNOS inhibitor treatment) NOS inhibition and the pathway was demonstrated to exert a greater contribution to the contractile responses in the large arteries than the small ones manifested by Y27632 [47, 48]. So whether ROCK pathway is essential target of HQD need further investigation to identify.

In summary, the present findings provide further insight into the potential efficacy of HQD in inhibiting 5/6 Nx-induced endothelial dysfunction and underlying mechanisms that contribute to protect against progression of CKD. As a classical formula, novel therapeutics that directly target anti-oxidative mechanism may potentially help reduce the high-risk complication. And the complicated composition and the potential clinical benefits of HQD confer more intensive investigation in progress.

\section{Acknowledgements}

This work was supported by the National Natural Science Foundation of China (81473480, 81403235); the Innovation Program of Talent Project of Putuo District (2014-A19) and Key Medical Discipline Project of Shanghai Municipal Health Bureau (ZK2015A18).

\section{Disclosure Statement}

None.

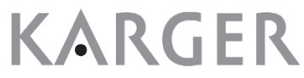




\section{Cellular Physiology Cell Physiol Biochem 2016;40:1354-1366

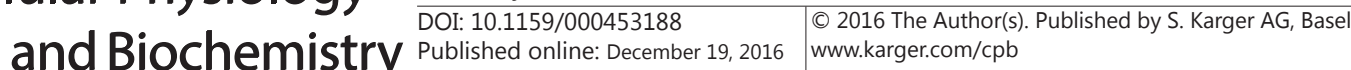 \\ Chu et al.: Huangqi Decoction Ameliorates Endothelial Dysfunction}

\section{References}

1 Davignon J, Ganz P: Role of endothelial dysfunction in atherosclerosis. Circulation 2004;109:III27-32.

2 Hirata Y, Sugiyama S, Yamamoto E, Matsuzawa Y, Akiyama E, Kusaka H, Fujisue K, Kurokawa H, Matsubara J, Sugamura K, Maeda H, Iwashita S, Jinnouchi H, Matsui K, Ogawa H: Endothelial function and cardiovascular events in chronic kidney disease. Int J Cardiol 2014;173:481-486.

3 D'Apolito M, Du X, Pisanelli D, Pettoello-Mantovani M, Campanozzi A, Giacco F, Maffione AB, Colia AL, Brownlee M, Giardino I: Urea-induced ROS cause endothelial dysfunction in chronic renal failure. Atherosclerosis 2015;239:393-400.

4 Kohan DE: Endothelin, hypertension and chronic kidney disease: new insights. Curr Opin Nephrol Hypertens 2010;19:134-139.

5 Kawano N, Emoto M, Mori K, Yamazaki Y, Urata H, Tsuchikura S, Motoyama K, Morioka T, Fukumoto S, Shoji T, Koyama H, Okuno Y, Nishizawa Y, Inaba M: Association of endothelial and vascular smooth muscle dysfunction with cardiovascular risk factors, vascular complications, and subclinical carotid atherosclerosis in type 2 diabetic patients. J Atheroscler Thromb 2012;19:276-284.

6 Modlinger PS, Wilcox CS, Aslam S: Nitric oxide, oxidative stress, and progression of chronic renal failure. Semin Nephrol 2004;24:354-365.

7 Kajimoto H, Kai H, Aoki H, Yasuoka S, Anegawa T, Aoki Y, Ueda S, Okuda S, Imaizumi T: Inhibition of eNOS phosphorylation mediates endothelial dysfunction in renal failure: new effect of asymmetric dimethylarginine. Kidney Int 2012;81:762-768.

8 Drummond GR, Selemidis S, Griendling KK, Sobey CG: Combating oxidative stress in vascular disease: NADPH oxidases as therapeutic targets. Nat Rev Drug Discov 2011;10:453-471.

9 Han F, Hui Z, Zhang S, Hou N, Wang Y, Sun X: Induction of haemeoxygenase-1 improves FFA-induced endothelial dysfunction in rat aorta. Cell Physiol Biochem 2015;35:1230-1240.

10 Zhang BQ, Hu SJ, Qiu LH, Zhu JH, Xie XJ, Sun J, Zhu ZH, Xia Q, Bian K: Effects of Astragalus membranaceus and its main components on the acute phase endothelial dysfunction induced by homocysteine. Vascul Pharmacol 2007;46:278-285.

11 Qiu LH, Xie XJ, Zhang BQ: Astragaloside IV improves homocysteine-induced acute phase endothelial dysfunction via antioxidation. Biol Pharm Bull 2010;33:641-646.

12 Yin Y, Qi F, Song Z, Zhang B, Teng J: Ferulic acid combined with astragaloside IV protects against vascular endothelial dysfunction in diabetic rats. Biosci Trends 2014;8:217-226.

13 Kharbanda C, Alam MS, Hamid H, Javed K, Bano S, Ali Y, Nazreen S, Haider S: Ameliorative effects of Trichosanthes dioica Extract in suppressing inflammatory mediators and attenuating oxidative stress. Planta Med 2015;81:348-356.

14 Bhattacharya S, Haldar PK: The triterpenoid fraction from Trichosanthes dioica root exhibits antiproliferative activity against Ehrlich ascites carcinoma in albino mice: involvement of possible antioxidant role. J Exp Ther Oncol 2012;9:281-290.

15 Lin Y, Zhu D, Qi J, Qin M, Yu B: Characterization of homoisoflavonoids in different cultivation regions of Ophiopogon japonicus and related antioxidant activity. J Pharm Biomed Anal 2010;52:757-762.

16 Thandavarayan RA, Giridharan VV, Arumugam S, Suzuki K, Ko KM, Krishnamurthy P, Watanabe K, Konishi T: Schisandrin B prevents doxorubicin induced cardiac dysfunction by modulation of DNA damage, oxidative stress and inflammation through inhibition of MAPK/p53 signaling. PLoS One 2015;10:e0119214.

17 Zhang LQ, Sa F, Chong CM, Wang Y, Zhou ZY, Chang RC, Chan SW, Hoi PM, Yuen Lee SM: Schisantherin A protects against 6-OHDA-induced dopaminergic neuron damage in zebrafish and cytotoxicity in SH-SY5Y cells through the ROS/NO and AKT/GSK3beta pathways. J Ethnopharmacol 2015;170:8-15.

18 Zhao J, Wang L, Cao AL, Jiang MQ Chen X, Wang Y, Wang YM, Wang H, Zhang XM, Peng W: HuangQi Decoction Ameliorates Renal Fibrosis via TGF-beta/Smad Signaling Pathway In Vivo and In Vitro. Cell Physiol Biochem 2016;38:1761-1774.

19 Jiang MQ, Wang L, Cao AL, Zhao J, Chen X, Wang YM, Wang H, Peng W: HuangQi Decoction Improves Renal Tubulointerstitial Fibrosis in Mice by Inhibiting the Up-Regulation of Wnt/beta-Catenin Signaling Pathway. Cell Physiol Biochem 2015;36:655-669.

20 Tapia E, Zatarain-Barron ZL, Hernandez-Pando R, Zarco-Marquez G, Molina-Jijon E, Cristobal-Garcia M, Santamaria J, Pedraza-Chaverri J: Curcumin reverses glomerular hemodynamic alterations and oxidant stress in 5/6 nephrectomized rats. Phytomedicine 2013;20:359-366. 


\section{Cellular Physiology Cell Physiol Biochem 2016;40:1354-1366 \begin{tabular}{l|l|l} 
and Biochemistry $\begin{array}{l}\text { DOI: 10.1159/000453188 } \\
\text { Published online: December 19, } 2016\end{array}$ & $\begin{array}{l}\text { (c) } 2016 \text { The Author(s). Published by S. Karger AG, Basel } \\
\text { www.karger.com/cpb }\end{array}$
\end{tabular} \\ Chu et al.: Huangqi Decoction Ameliorates Endothelial Dysfunction}

21 Mao GX, Zheng LD, Cao YB, Chen ZM, Lv YD, Wang YZ, Hu XL, Wang GF, Yan J: Antiaging effect of pine pollen in human diploid fibroblasts and in a mouse model induced by D-galactose. Oxid Med Cell Longev 2012;2012:750963.

22 Chen W, Liu DJ, Huo YM, Wu ZY, Sun YW: Reactive oxygen species are involved in regulating hypocontractility of mesenteric artery to norepinephrine in cirrhotic rats with portal hypertension. Int J Biol Sci 2014;10:386-395.

23 Dahboul F, Leroy P, Maguin Gate K, Boudier A, Gaucher C, Liminana P, Lartaud I, Pompella A, Perrin-Sarrado C: Endothelial gamma-glutamyltransferase contributes to the vasorelaxant effect of S-nitrosoglutathione in rat aorta. PLoS One 2012;7:e43190.

24 Hasdan G, Benchetrit S, Rashid G, Green J, Bernheim J, Rathaus M: Endothelial dysfunction and hypertension in 5/6 nephrectomized rats are mediated by vascular superoxide. Kidney Int 2002;61:586590.

25 Toba H, Morishita M, Tojo C, Nakano A, Oshima Y, Kojima Y, Yoshida M, Nakashima K, Wang J, Kobara M, Nakata T: Recombinant human erythropoietin ameliorated endothelial dysfunction and macrophage infiltration by increasing nitric oxide in hypertensive 5/6 nephrectomized rat aorta. Eur J Pharmacol 2011;656:81-87.

26 Tatematsu S, Wakino S, Kanda T, Homma K, Yoshioka K, Hasegawa K, Sugano N, Kimoto M, Saruta T, Hayashi K: Role of nitric oxide-producing and -degrading pathways in coronary endothelial dysfunction in chronic kidney disease. J Am Soc Nephrol 2007;18:741-749.

27 Maranon RO, Joo Turoni C, Karbiner MS, Salas N, Peral de Bruno M: Antioxidant treatment reverts increased arterial Basal tone and oxidative stress in nephrectomized (5/6) hypertensive rats. Int J Hypertens 2013;2013:863067.

28 Morris ST, McMurray JJ, Rodger RS, Jardine AG: Impaired endothelium-dependent vasodilatation in uraemia. Nephrol Dial Transplant 2000;15:1194-1200.

29 Shimizu MH, Coimbra TM, de Araujo M, Menezes LF, Seguro AC: N-acetylcysteine attenuates the progression of chronic renal failure. Kidney Int 2005;68:2208-2217.

30 Quiroz Y, Ferrebuz A, Romero F, Vaziri ND, Rodriguez-Iturbe B: Melatonin ameliorates oxidative stress, inflammation, proteinuria, and progression of renal damage in rats with renal mass reduction. Am J Physiol Renal Physiol 2008;294:F336-344.

31 Cruz C, Correa-Rotter R, Sanchez-Gonzalez DJ, Hernandez-Pando R, Maldonado PD, Martinez-Martinez CM, Medina-Campos ON, Tapia E, Aguilar D, Chirino YI, Pedraza-Chaverri J: Renoprotective and antihypertensive effects of S-allylcysteine in 5/6 nephrectomized rats. Am J Physiol Renal Physiol 2007;293:F1691-1698.

32 Tain YL, Freshour G, Dikalova A, Griendling K, Baylis C: Vitamin E reduces glomerulosclerosis, restores renal neuronal NOS, and suppresses oxidative stress in the 5/6 nephrectomized rat. Am J Physiol Renal Physiol 2007;292:F1404-1410.

33 Briones AM, Touyz RM: Oxidative stress and hypertension: current concepts. Curr Hypertens Rep 2010;12:135-142.

34 Schnackenberg CG, Welch WJ, Wilcox CS: Normalization of blood pressure and renal vascular resistance in SHR with a membrane-permeable superoxide dismutase mimetic: role of nitric oxide. Hypertension 1998;32:59-64.

35 Somers MJ, Mavromatis K, Galis ZS, Harrison DG: Vascular superoxide production and vasomotor function in hypertension induced by deoxycorticosterone acetate-salt. Circulation 2000;101:1722-1728.

36 Heitzer T, Wenzel U, Hink U, Krollner D, Skatchkov M, Stahl RA, MacHarzina R, Brasen JH, Meinertz T, Munzel T: Increased NAD(P)H oxidase-mediated superoxide production in renovascular hypertension: evidence for an involvement of protein kinase C. Kidney Int 1999;55:252-260.

37 Griendling KK, Sorescu D, Ushio-Fukai M: NAD(P)H oxidase: role in cardiovascular biology and disease. Circ Res 2000;86:494-501.

38 Pedro-Botet J, Covas MI, Martin S, Rubies-Prat J: Decreased endogenous antioxidant enzymatic status in essential hypertension. J Hum Hypertens 2000;14:343-345.

39 Taddei S, Virdis A, Ghiadoni L, Magagna A, Favilla S, Pompella A, Salvetti A: Restoration of nitric oxide availability after calcium antagonist treatment in essential hypertension. Hypertension 2001;37:943-948.

40 Cai H, Harrison DG: Endothelial dysfunction in cardiovascular diseases: the role of oxidant stress. Circ Res 2000;87:840-844. 


\section{Cellular Physiology Cell Physiol Biochem 2016;40:1354-1366 \begin{tabular}{l|l|l} 
DOI: 10.1159/000453188 & $\begin{array}{l}\text { O 2016 The Author(s). Published by S. Karger AG, Basel } \\
\text { www.karger.com/cpb }\end{array}$
\end{tabular} \\ Chu et al.: Huangqi Decoction Ameliorates Endothelial Dysfunction}

41 Jin L, Ying Z, Webb RC: Activation of Rho/Rho kinase signaling pathway by reactive oxygen species in rat aorta. Am J Physiol Heart Circ Physiol 2004;287:H1495-1500.

42 Virdis A, Neves MF, Amiri F, Touyz RM, Schiffrin EL: Role of NAD(P)H oxidase on vascular alterations in angiotensin II-infused mice. J Hypertens 2004;22:535-542.

43 Lodi F, Cogolludo A, Duarte J, Moreno L, Coviello A, Peral De Bruno M, Vera R, Galisteo M, Jimenez R, Tamargo J, Perez-Vizcaino F: Increased NADPH oxidase activity mediates spontaneous aortic tone in genetically hypertensive rats. Eur J Pharmacol 2006;544:97-103.

44 Kizub IV, Pavlova 00, Johnson CD, Soloviev AI, Zholos AV: Rho kinase and protein kinase C involvement in vascular smooth muscle myofilament calcium sensitization in arteries from diabetic rats. Br J Pharmacol 2010;159:1724-1731.

45 Yao L, Chandra S, Toque HA, Bhatta A, Rojas M, Caldwell RB, Caldwell RW: Prevention of diabetesinduced arginase activation and vascular dysfunction by Rho kinase (ROCK) knockout. Cardiovasc Res 2013;97:509-519.

46 Cicek FA, Kandilci HB, Turan B: Role of ROCK upregulation in endothelial and smooth muscle vascular functions in diabetic rat aorta. Cardiovasc Diabetol 2013;12:51.

47 Williams J, Bogwu J, Oyekan A: The role of the RhoA/Rho-kinase signaling pathway in renal vascular reactivity in endothelial nitric oxide synthase null mice. J Hypertens 2006;24:1429-1436.

48 Asano M, Nomura Y: Comparison of inhibitory effects of Y-27632, a Rho kinase inhibitor, in strips of small and large mesenteric arteries from spontaneously hypertensive and normotensive Wistar-Kyoto rats. Hypertens Res 2003;26:97-106. 